\title{
Quantitative analysis of iron-stress related proteins in Thalassiosira weissflogii: measurement of flavodoxin and ferredoxin using HPLC
}

\author{
Gregory J. Doucette ${ }^{1, *}$, Deana L. Erdner ${ }^{2}$, M. Louisa Peleato ${ }^{3}$, James J. Hartman ${ }^{4}$, \\ Donald M. Anderson ${ }^{2}$
}

${ }^{1}$ National Marine Fisheries Service/SEFSC, Charleston Laboratory, PO Box 12607, Charleston, South Carolina 29422-2607, USA

${ }^{2}$ Biology Department, Woods Hole Oceanographic Institution, Woods Hole, Massachusetts 02543, USA

${ }^{3}$ Departamento de Bioquimica y Biologia Molecular y Celular, Facultad de Ciencias, Universidad de Zaragoza, E-50009 Zaragoza, Spain

${ }^{4}$ Department of Biochemistry and Biophysics, University of California, San Francisco, California 94143, USA

\begin{abstract}
The controversy surrounding the question of whether iron limits phytoplankton production in high-nutrient, low-chlorophyll regions of the world's oceans has stimulated research on numerous fronts, including the search for diagnostic indicators of phytoplankton iron nutritional status. Flavodoxin (Flv), an iron-independent protein capable of catalyzing many of the same reactions as the non-heme, iron-sulfur protein ferredoxin (Fd), is produced by certain prokaryotic and eukaryotic organisms in response to iron stress. Few eukaryotic marine phytoplankton species have been examined for their ability to synthesize Flv, primarily due to the lack of a suitable analytical method. In response to this need, a high performance liquid chromatography (HPLC)/photodiode array detection method was developed for the separation and identification of Flv and Fd in crude protein extracts of algal samples. The utility of this technique was then demonstrated with a study of Flv and Fd production by the diatom Thalassiosira weissflogii, a eukaryotic marine phytoplankton species. Flv was detected in iron-limited $T$. weissflogiu at levels about 20 -fold greater (by molecules) than in iron-replete cells. Although constitutive expression of this protein under iron-sufficient conditions was observed, actual levels were very low. By comparison, the iron-containing protein Fd was abundant in ironreplete cells but undetectable in iron-limited cells (limit of detection ca $1 \mu \mathrm{g} \mathrm{ml}^{-1}$ ). If Flv (by molecules) is expressed as a percentage of the combined pool of Flv and Fd, [Flv/(Flv $+F d)] \times 100$, values fall between ca 10 and $15 \%(n=6)$ for iron-replete cells, but are consistently $100 \%$ under Fe-limiting conditions ( $n=5)$, where Fd is below detection limits. Thus, the constitutive nature of Flv production by $T$. weissflogii does not preclude its possible use as a diagnostic indicator of iron stress. The HPLC method developed during this study, in conjunction with cellular level techniques (e.g. antibodies, nucleic acid probes), will permit a rapid, accurate assessment of phytoplankton iron nutritional status without the need for intrusive techniques such as bottle incubations. Additional laboratory and field studies are now needed to evaluate the applicability of Flv and Fd relative abundance as a diagnostic indicator of iron limitation in a broad range of species and natural phytoplankton communities.
\end{abstract}

KEY WORDS: Flavodoxin Ferredoxin - HPLC I Iron limitation · Phytoplankton · Biomarker

\section{INTRODUCTION}

The hypothesis that iron limits phytoplankton production in large, nutrient-rich regions of the world's

-E-mail: greg_doucette@ccgate.ssp.nmfs.gov oceans has attracted considerable attention since being put forth by Martin and colleagues in a series of publications (Martin \& Fitzwater 1988, Martin et al. 1989, 1990, 1991, Martin 1990). This body of work suggests that the occurrence of 'high-nutrient, lowchlorophyll' (HNLC) areas, characterized by a low 
phytoplankton standing crop in the presence of excess major nutrients (i.e. nitrate and phosphate), is due to limitation of phytoplankton growth by iron. However, the 'iron hypothesis', based primarily on bioassay data and measurements of dissolved iron, is not without its detractors and has been countered with several alternative hypotheses (reviewed in Chisholm \& Morel 1991). Recently, the case for iron's role as a growth-limiting nutrient in the HNLC Equatorial Pacific was strengthened considerably by a mesoscale (ca $64 \mathrm{~km}^{2}$ ) iron enrichment experiment (Coale et al. 1994a) showing a clear enhancement of phytoplankton biomass and productivity in response to the iron addition (Coale et al. 1994b). In any event, the controversy over what does, in fact, limit phytoplankton growth in such HNLC waters has stimulated research on numerous fronts. One of these areas involves the search for diagnostic indicators (so-called biomarkers) of phytoplankton iron nutritional status which can be rapidly assessed in a field situation without the need for bottle incubations or large-scale enrichment experiments. Analytical determinations of these biomarkers on bulk plankton samples would provide valuable, community-level measurements of iron status. Resolution at the level of individual phytoplankton cells would also be possible using antibody- and/or nucleic acid-based probe technologies.

Given the important contribution of both pro- and eukaryotic species to phytoplankton production, the search for an indicator of iron stress should include both groups. A promising direction is suggested by a survey of the bacterial and cyanobacterial literature, which indicates that a common response to iron stress among prokaryotes is to reduce levels of ferredoxin (Fd), an evolutionarily conserved non-heme, iron-sulfur protein, while turning on production of flavodoxin (Flv), a flavoprotein capable of catalyzing many of the same reactions as $F d$ yet requiring no iron for its biosynthesis (e.g. Knight \& Hardy 1966, Hutber et al. 1977, Drummond 1985, Sandmann et al. 1990). While the production of Flv is frequently induced only by decreasing levels of iron bioavailability, certain prokaryotes can also synthesize this flavoprotein constitutively (Vetter \& Knappe 1971, Klugkist et al. 1986). In the few eukaryotic algae that have been investigated for Flv production, variability similar to that found in prokaryotes has been observed (Zumft \& Spiller 1971, Fitzgerald et al. 1978, Entsch et al. 1983, Price et al. 1991). However, since only 1 study included representatives of the marine phytoplankton (La Roche et al. 1993), a more comprehensive screening of this group is needed to fully assess the potential for Flv to serve as a biomarker for the iron nutritional status of these algae.
A key requirement for screening a large number of diverse algal taxa for the ability to synthesize Flv is an easily accessible analytical method with broad applicability. In our opinion, analysis of crude protein extracts by high performance liquid chromatography (HPLC) coupled with UV photodiode array detection (PDA) meets these specifications. The principal advantage of this approach is that HPLC/PDA provides the means to acquire an absorbance spectrum for a selected chromatogram peak, and thus a physical 'fingerprint' of the compound. Furthermore, the separation chemistry can be applied to preparative scale samples in order to purify compounds for additional work such as chemical characterization or antibody production. Although liquid chromatography methods for Flv (and Fd) have been reported (Fish \& Sanders-Loehr 1987, Jones 1988, Sandmann et al. 1990), all rely on the technique of fast protein liquid chromatography (FPLC) and require specialized equipment apart from conventional HPLC components. Our aim, therefore, was to develop an HPLC protocol for the separation and identification of Flv and Fd based on FPLC methods established previously for these proteins. The utility of this HPLC technique was then demonstrated with an investigation of Flv and Fd production in iron-replete and iron-limited batch cultures of the diatom Thalassiosira weissflogii, a eukaryotic marine phytoplankton species.

\section{MATERIALS AND METHODS}

Phytoplankton cultures and maintenance. The eukaryotic marine phytoplankton species examined during this study was the diatom Thalassiosira weissflogii (Grun.) Fryxell et Hasle (strain ACTIN). Cultures were maintained in $0.45 \mu \mathrm{m}$ filtered Vineyard Sound (MA, USA) seawater (31 ppt) supplemented with a modified ESNW enrichment (Harrison et al. 1980). In this case, an equimolar concentration of $\mathrm{Na}_{2} \mathrm{HPO}_{4}$ was substituted for $\mathrm{Na}_{2}$ glyceroPO , and the trace metals of Brand et al. (1983), to which was added $10^{-8} \mathrm{M}$ $\mathrm{H}_{2} \mathrm{SeO}_{3}$, were used. EDTA was present at a concentration of $10^{-6} \mathrm{M}$ and was added as a solution combined with $10^{-6} \mathrm{M} \mathrm{FeCl}_{3}$. Cultures, including those used for experiments, were maintained at $20^{\circ} \mathrm{C}$ on a $14 \mathrm{~h}$ light: $10 \mathrm{~h}$ dark cycle, with ca $200 \mu \mathrm{E} \mathrm{m}^{-2} \mathrm{~s}^{-1}$ irradiance supplied by cool-white fluorescent bulbs.

Experimental procedures. Batch cultures utilized during this study were of 2 types: iron-replete and ironlimited. Six iron-replete cultures (1.5 I volume) were grown in 2.81 borosilicate Fernbach flasks using the medium described above for maintenance, except that the iron and EDTA concentrations were adjusted to $10^{-5} \mathrm{M}$ and $10^{-4} \mathrm{M}$, respectively. Three of these cultures were harvested (see below for methods) at mid-expo- 
nential phase and the remaining 3 were harvested in early stationary phase. Similarly, 6 ironlimited cultures (2 1 total volume) were grown in acid- cleaned 2.81 borosilicate Fernbach flasks, with 3 flasks each harvested at the mid-log and early stationary points on the growth curve. The composition of the medium used to limit available iron was the same as that employed for maintenance, with the total iron concentration reduced from $10^{-6} \mathrm{M}$ to $2 \times 10^{-7} \mathrm{M}$ and EDTA increased from $10^{-6} \mathrm{M}$ to $2 \times 10^{-6} \mathrm{M}$. Culture vessels and media were sterilized by autoclaving. For the purposes of this study, cells obtained at both mid-log and early stationary phase of the low iron addition cultures are referred to as iron-limited, and identified as being harvested during exponential (EXP) or early stationary (STN) phase, where appropriate. Confirmation that cell division ceased due to a lack of biologically available iron in the culture medium was obtained by bioassays, which showed renewed growth following the addition of iron only, but no response from either re-supply of all noniron enrichments or no addition (data not shown).

At the appropriate points in the growth curve, cultures were sampled for cell counts and chlorophyll a (chl a) determinations, then harvested by centrifugation, followed by aspiration of the supernatant, and freezing/ storage of the cell pellet at $-80^{\circ} \mathrm{C}$ until extracted. Crude extracts of acetone-precipitated, solubilized protein (containing Flv and Fd) were prepared as follows: Cell pellets were thawed in $4 \mathrm{ml}$ of freshly prepared, ice-cold homogenization buffer [50 mM Tris-acetate, $10 \mu \mathrm{M}$ PMSF (phenylmethylsulfonyl fluoride), $1 \mathrm{mM}$ EDTA, $1 \mathrm{mM} \mathrm{B}$-mercaptoethanol, final $\mathrm{pH}=8.0$ ] and sonicated for $30 \mathrm{~s}$ on ice using a Branson Model W-185 sonicator (Branson Sonic Power Co., Danbury, CT, USA). Complete disruption of cells was confirmed by microscopic examination. The cell-free homogenate was then combined with 9 volumes of $100 \%$ acetone and extracted by agitating for $1 \mathrm{~h}$ at $-20^{\circ} \mathrm{C}$ in order to quantitatively precipitate proteins and to remove pigments and other non-polar constituents. Following acetone extraction, samples were centrifuged for $15 \mathrm{~min}$ at $15000 \times \mathrm{g}\left(4^{\circ} \mathrm{C}\right)$, the supernatant aspirated, and the pellet allowed to dry at room temperature forming an acetone powder. The acetone powder was resuspended in $2.2 \mathrm{ml}$ of ice-cold homogenization buffer containing no B-mercaptoethanol (= sample buffer), and extracted by agitation for ca $24 \mathrm{~h}$ at $4^{\circ} \mathrm{C}$. Cell debris was pelleted by centrifuging for $20 \mathrm{~min}$ at $10000 \times g\left(4^{\circ} \mathrm{C}\right)$, after which the supernatant containing the solubilized proteins (hereafter referred to as the crude protein extract) was removed and stored at $-20^{\circ} \mathrm{C}$ until the time of analysis.

Analytical techniques. HPLC/PDA: All HPLC analyses were performed with a Varian model 5000 Liquid Chromatograph (Varian Associates, Sugar Land, TX, USA), coupled with UV PDA detection using a Hewlett-
Packard model 1040A Diode Array Detector (HewlettPackard Co., Andover, MA, USA). Our HPLC protocol was based on previously described FPLC methods for Flv and Fd (Fish \& Sanders-Loehr 1987, Jones 1988, Sandmann et al. 1990). The column used in these FPLC procedures was a Mono $Q$ anion exchange column (Pharmacia, Piscataway, NJ, USA). The properties of this column are closely approximated by a Hydropore 5-SAX column (Rainin Instrument Co., Inc., Woburn, MA, USA), which was therefore selected for use in the HPLC system. Several different mobile phases and elution gradients were tested in order to optimize detection of purified Chlorella Flv II (isolated and prepared by M.L.P.) and spinach Fd (Sigma Chemical Co., St. Louis, MO, USA). The most satisfactory results were obtained with a linear salt gradient $(0.1$ to $0.7 \mathrm{M} \mathrm{NaCl}$ over $35 \mathrm{~min}$ ) made up in a $20 \mathrm{mM}$ sodium phosphate buffer ( $\mathrm{pH} 7.0$ ) at a flow rate of $0.6 \mathrm{ml} \mathrm{min}^{-1}$. These conditions were used in our analyses of crude protein extracts prepared as outlined above. The column was regenerated between runs by briefly washing with $1 \mathrm{M}$ $\mathrm{NaCl}$, then flushing thoroughly with buffer only. Eluted proteins were detected by PDA and absorbance spectra collected for chromatogram peaks of interest. For crude protein extracts from the diatom Thalassiorsira weissflogii, identification of peaks corresponding to Flv and Fd was based on absorbance spectra for these proteins as isolated and purified from other systems (Smillie 1965, Knight \& Hardy 1966, 1967). Quantification of $T$. weissflogii Flv and Fd was based on Chlorella Flv II and spinach Fd, respectively. We recognize that this method of quantification yields only estimates of Flv and Fd, which are nonetheless suitable for assessing relative differences in these proteins.

Cell concentrations: Cell concentrations were obtained by direct microscopic counts of Lugol's-preserved samples (4 replicates of at least 100 cells counted per sample) in a Fuchs-Rosenthal haemacytometer.

Chlorophyll a: Chl a was determined on triplicate samples per flask according to a slightly modified version of the Parsons et al. (1984) method. Cells collected on Millipore GSWP membranes $(0.22 \mu \mathrm{m} ; 25 \mathrm{~mm}$ diameter) were extracted without grinding in $90 \%$ acetone overnight in the dark at $4^{\circ} \mathrm{C}$ (note: membranes dissolved in extraction solvent). Chl a concentrations in the extract were measured fluorometrically and values were corrected for the presence of any phaeopigments.

Soluble protein: Concentrations of acetone-precipitated, buffer-solubilized protein in crude extracts containing Flv and/or Fd were determined using the BCA protein assay reagent (Pierce Chemical Co., Rockford, IL, USA). The term soluble protein hereafter refers to that protein fraction solubilized in sample buffer following acetone precipitation and quantified in the manner described. 


\section{RESULTS}

\section{Flv and Fd standards}

Absorbance spectra for Chlorella Flv II and spinach Fd reference standards obtained from HPLC/PDA analyses are shown in Fig. $1 \mathrm{~A} \& \mathrm{~B}$, respectively. The spectrum for Chlorella Flv II showed absorbance maxima at 380 and $466 \mathrm{~nm}$, while wavelengths of maximum absorbance for the spinach Fd occurred at 330 , 423 and $466 \mathrm{~nm}$. These spectra were determined to be characteristic of these proteins as described previously from other sources (see 'Materials and Methods'). Our
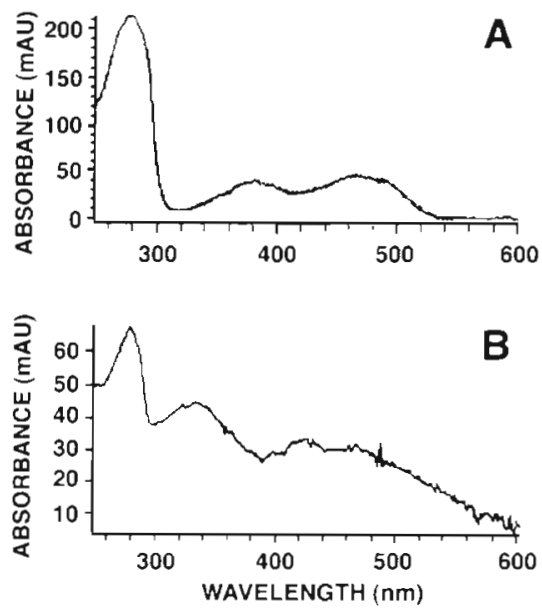

Fig. 1. (A) UV absorbance spectrum of Chlorella Flv II reference standard ( $73 \mu \mathrm{g}$ injected); absorbance maxima: $380,466 \mathrm{~nm}$. (B) UV absorbance spectrum of spinach Fd reference standard (50 $\mu \mathrm{g}$ injected); absorbance maxima: 330, 423, $466 \mathrm{~nm}$ limit of detection with the HPLC/PDA for both Flv and Fd was about $1 \mu \mathrm{g} \mathrm{ml} \mathrm{ml}^{-1}$, below which reliable absorbance spectra could not be obtained. A linear response with increasing protein concentration was observed from 2 to $100 \mu \mathrm{g} \mathrm{ml}^{-1}$ in the case of Flv, while Fd exhibited linearity between 1 and $100 \mu \mathrm{g} \mathrm{m}^{-1}$.

\section{Flv and Fd in Thalassiosira weissflogii}

Direct analysis of crude protein extracts by HPLC/PDA allowed the separation and identification of Flv and Fd in Thalassiosira weissflogii, when present. Iron-replete and iron-limited cultures of $T$. weissflogii both showed a clear presence of Flv, while Fd was detected only under iron-sufficient conditions (Figs. 2A \& 3A). Identities of chromatogram peaks were confirmed through their respective absorbance spectra obtained with the PDA detector (Figs, 2B, C \& 3B).

Relative differences in levels of Flv and Fd as a function of iron status were noted (Table 1). Flv was determined to be present in cells of the Fe-replete cultures at both EXP $\left(1.50 \times 10^{5}\right.$ molecules cell $\left.{ }^{-1}\right)$ and STN phase $\left(1.23 \times 10^{5}\right.$ molecules cell $\left.{ }^{-1}\right)$. Nevertheless, dramatically higher Flv levels (ca 20 -fold) were observed in the low iron addition cultures at the corresponding growth phase. Iron-limited cells in EXP phase contained $2.90 \times 10^{6}$ molecules cell ${ }^{-1}$, while values were slightly higher at $3.74 \times 10^{6}$ molecules cell ${ }^{-1}$ at the onset of plateau phase upon depletion of biologically available iron. Fd, in contrast to Flv, was present at both EXP $\left(1.37 \times 10^{6}\right.$ molecules cell $\left.{ }^{-1}\right)$ and STN phases $\left(0.56 \times 10^{6}\right.$ molecules cell $\left.{ }^{-1}\right)$ of Fe-replete cultures, yet this iron-dependent protein could not be detected in
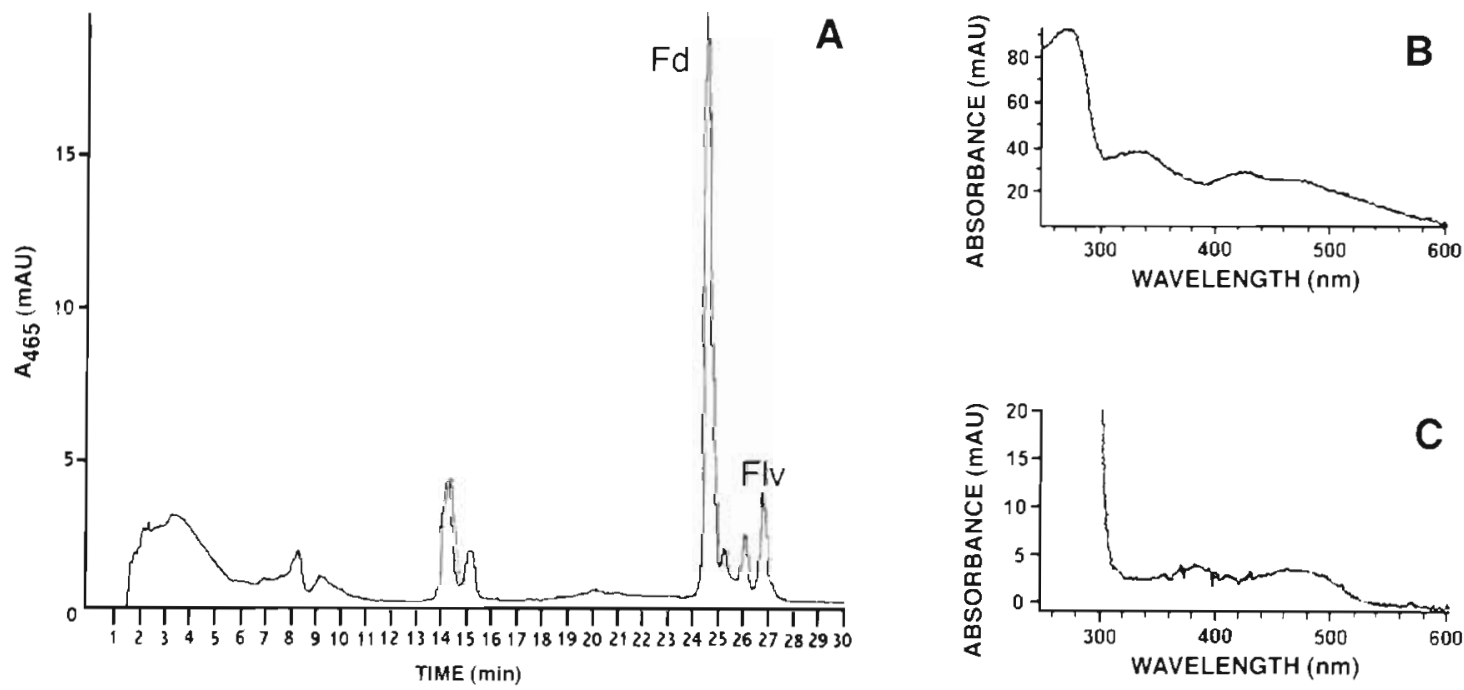

Fig. 2. Thalassiosira weissflogii. (A) Representative HPLC/PDA trace of crude protein extract from a stationary-phase, ironreplete culture. (B) UV absorbance spectrum of $\mathrm{Fd}$ (retention time $24.38 \mathrm{~min}$ ); absorbance maxima: $331,429,466 \mathrm{~nm}$. (C) UV absorbance spectrum of Flv (retention time $26.68 \mathrm{~min}$ ); absorbance maxima: $380,460 \mathrm{~nm}$ 


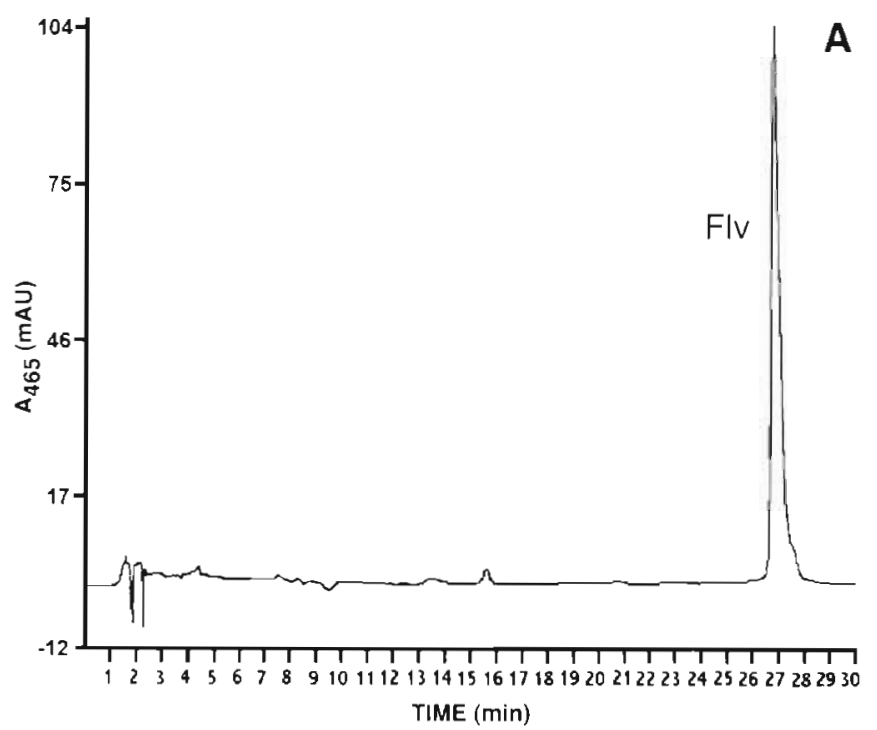

any Fe-limited cultures regardless of growth phase. If Flv and Fd levels (by molecules) are incorporated into an index expressing Flv as a percentage of the combined pool of Flv and Fd,

$$
[\mathrm{Flv} /(\mathrm{Flv}+\mathrm{Fd})] \times 100,
$$

values for Fe-replete cultures range from about 10 to $15 \%$, while the index is consistently $100 \%$ under conditions of iron stress, reflecting the undetectable levels of Fd in these cells (Table 1).

Flv accounted for less than $1 \%$ of soluble protein (by weight) in cells of all Fe-replete cultures, but increased markedly to about $15 \%$ in Fe-limited cultures for either EXP or STN phases. By comparison, Fd remained at a relatively constant 1 to $2 \%$ of soluble protein in $\mathrm{Fe}$ replete cells irrespective of growth phase. As already noted, Fd was not detected under conditions of iron stress. The chl a content of cells in the low Fe addition cultures was 2-to 3-fold lower than for those cells at the same growth phase under iron-sufficient conditions.

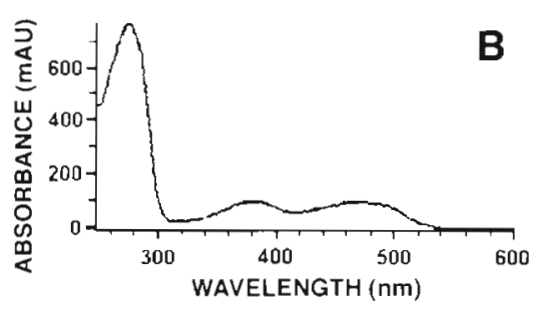

Fig. 3. Thalassiosira weissflogii. (A) Representative HPLC/PDA trace of crude protein extract from a stationary phase, iron-limited culture. (B) UV absorbance spectrum of Flv (retention time $26.68 \mathrm{~min}$ ); absorbance maxima: $382,465 \mathrm{~nm}$

\section{DISCUSSION}

Development of a new HPLC/PDA technique for the analysis of $\mathrm{Flv}$ and $\mathrm{Fd}$ in crude protein extracts from algae allowed us to obtain real-time spectral absorbance signatures of chromatogram peaks, which provided unambiguous proof of the presence of Flv in both iron-replete and iron-stressed cells of Thalassiosira weissflogii. While it was not possible to determine absolute quantities of Flv or Fd present in extracts, due to a lack of purified reference standards from $T$. weissflogii, quantification based on measurements of these same proteins isolated from other species permitted us to assess their relative changes as a function of culture iron status. Our data are consistent with the recent findings of LaRoche et al. (1993), who used western blot techniques to document the presence of Flv in iron-stressed, marine eukaryotic phytoplankton for the first time. Extrapolation of their results to broader issues of marine ecology is constrained,

Table 1 Thalassiosira werssflogii. Biochemical characteristics of iron-replete $(+F e)$ and iron-limited (-Fe) batch cultures sampled at either the mid-exponential (EXP) or the early stationary (STN) phase. Three replicates were performed for all experiments except $-F e / S T N$, where $n=2$. Values in parentheses are $\pm S D$. nd: not detectable

\begin{tabular}{|c|c|c|c|c|c|c|c|c|c|}
\hline $\begin{array}{l}\text { Iron } \\
\text { status }\end{array}$ & $\begin{array}{c}\text { Chl a } \\
\left(\mathrm{fg} \mathrm{cell}^{-1}\right)\end{array}$ & $\begin{array}{l}\text { Soluble } \\
\text { protein } \\
(\text { pg cell- })\end{array}$ & $\begin{array}{c}\text { Fd } \\
\text { (molecules } \\
\text { cell }{ }^{-1} \times 10^{5} \text { ) }\end{array}$ & $\begin{array}{c}F d \\
\left(\text { fg cell }{ }^{-1}\right)\end{array}$ & $\begin{array}{c}\text { Flv } \\
(\text { molecules } \\
\left.\text { cell }^{-1} \times 10^{5}\right)\end{array}$ & $\begin{array}{c}\text { Flv } \\
\left(\text { f g cell }{ }^{-1}\right)\end{array}$ & $\begin{array}{l}\text { Fd \% } \\
\text { sol prot } \\
(w t / w t)\end{array}$ & $\begin{array}{l}\text { Flv \% } \\
\text { sol prot } \\
\text { (wt/wt) }\end{array}$ & $\begin{array}{l}{[\text { Flv } /(\text { Flv }+} \\
\text { Fd) }] \times 100\end{array}$ \\
\hline \multicolumn{10}{|l|}{ EXP } \\
\hline$+\mathrm{Fe}$ & $223(6)$ & $1.08(0.11)$ & $13.7(0.75)$ & $26.3(1.5)$ & $1.50(0.08)$ & $5.3(0.6)$ & $2.46(0.29)$ & $0.50\{0.05\}$ & $9.9(1.0)$ \\
\hline$-\mathrm{Fe}$ & $130(17)$ & $0.68(0.06)$ & nd & nd & $29.0(4.0)$ & $109(15.6)$ & nd & $15.31(0.97)$ & $100(0)$ \\
\hline \multicolumn{10}{|l|}{ STN } \\
\hline$+\mathrm{Fe}$ & $307(32)$ & $0.96(0.08)$ & $5.62(0.11)$ & $17.3(11.0)$ & $1.23(0.48)$ & $4.6(1.5)$ & $1.10(0.05)$ & $0.50(0.20)$ & $14.8(3.9)$ \\
\hline$-\mathrm{Fe}$ & $110(0)$ & $0.85(0.04)$ & nd & nd & $37.4(2.8)$ & $140(14.1)$ & nd & $16.35(0.98)$ & $100(0)$ \\
\hline
\end{tabular}


however, by the limitations of immunodetection methods, which depend on antibody cross-reactivity among algal classes or species for detection. Moreover, western blots thus far yield only a semi-quantitative indication of the presence of one of the 2 proteins involved in this nutritional strategy. Here we described a technique that allowed the simultaneous determination and quantification of both Flv and Fd in phytoplankton extracts. The sensitivity of this method permitted us to demonstrate low-level, constitutive production of Flv by $T$. weissflogii under iron-replete conditions. Flv alone may thus not be a suitable diagnostic indicator of iron limitation, but the relative abundance of Flv and Fd does appear to provide the needed resolution.

An important observation relevant to the search for indicators of phytoplankton iron nutritional status is that even though Flv was synthesized constitutively by Thalassiosira weissflogii, substantial increases (ca 20fold) in the Flv content of cells growing under conditions of iron stress occurred (Table 1). Furthermore, when Flv was expressed as a percentage of the combined pool of Flv and Fd (Eq. 1), this index very clearly distinguished iron-replete from iron-limited cells. Vigorously growing, Fe-replete cells of this diatom contained almost 10 times as much Fd as Flv by molecules (index $=10$ to $15 \%$ ), but when growth was limited by iron, Fd declined to undetectable levels, while Flv was enriched by a factor of about 20 (index $=100 \%$ ). Changes of this magnitude in Flv and Fd with iron stress are generally far greater than those documented for other eukaryotic algae and cyanobacteria for which such data are available (e.g. Smillie \& Entsch 1971, Hutber et al. 1977, Entsch et al. 1983, Fish \& SandersLoehr 1987, Jones 1988). Our results for $T$. weissflogii suggest that combining Flv and Fd levels into a single expression, such as that given by Eq. (1), shows promise as an indicator of iron nutritional status in eukaryotic marine phytoplankton capable of producing Flv. This relationship even appears to hold true for species exhibiting a constitutive Flv. The actual sensitivity of an 'index' based on this expression remains uncertain and will require determination of Flv and $\mathrm{Fd}$ for cells grown under a range of iron-limited growth conditions.

The accuracy of this index relies largely on the relative efficiency with which Flv and Fd are extracted when present in a cell. Based on several experiments (data not shown) in which sodium dodecyl sulfate was used to solubilize any protein remaining in the acetone powder following a $24 \mathrm{~h}$ extraction with sample buffer (see 'Materials and Methods'), western blots indicated that less than $1 \%$ of the total Flv and Fd did not appear in the final crude protein extract. The comparable extraction efficiency of Flv and Fd is not unexpected considering their high degree of similarity in terms of solubility, charge, and isoelectric point. In addition, since the index described above is based on the abundance of these proteins relative to each other, quantitative recovery is not essential and the index value will not be affected, providing both Flv and Fd are underestimated to the same extent (i.e. exhibit equal loss rates) and levels do not fall below detection limits. The actual numerical values obtained for this index do, nevertheless, remain a valid means of comparing samples, and will be essential for dealing with a variety of field sample types which are unlikely to be extracted with equal efficiency.

Our objective in developing the HPLC/PDA method used in this study was to facilitate screening of diverse algal taxa for the ability to synthesize Flv under conditions of iron stress. Such an effort is essential for evaluating the suitability of Flv to serve as a diagnostic indicator of phytoplankton iron nutritional status. One advantage of the HPLC/PDA technique is that it is not subject to many of the specificity constraints imposed by alternative methods. For example, an antibody may not cross-react with a compound slightly modified from the antigen against which it was produced. Such minor variations are likely to occur among flavodoxins originating from different classes of algae. Indeed, preliminary trials (G.J.D. \& D.L.E. unpubl. data) have indicated that antibodies produced against Flv isolated from the cyanobacterium Anabaena do not cross-react with our Flv reference standard, Chlorella Flv II. That flavodoxins from these 2 sources were, in fact, chemically distinct was confirmed by their different chromatographic retention times (data not shown). Nevertheless, absorbance spectra obtained with the PDA detector for these proteins, one eukaryotic and the other prokaryotic in nature, were both easily identified as Flv. Thus, while it appears that the successful detection of Flv in a species may rely on raising antibodies against proteins isolated from closely-related species (e.g. LaRoche et al. 1993), the HPLC/PDA approach should provide a robust means for identifying Flv across a broad range of algal groups.

Apart from the variation noted above in the combined Flv and Fd index as a function of Thalassiosira weissflogii iron status, quantitative changes in the Flv component of this index deserve comment. Our calculations show that Flv accounts for about $15 \%$ of the soluble protein (by weight) in $T$. weissflogii under conditions of iron stress, exceeding Fe-replete levels by ca 30 -fold irrespective of culture phase (Table 1). The presence of Flv at such high levels in Fe-stressed as compared to Fe-replete $T$. weissflogii cells clearly indicates that the biosynthesis of this protein is modulated in response to iron-limiting growth conditions. The presence of this strategy, coupled with the high iron requirement of this coastal diatom (Harrison \& 
Morel 1986), suggests that phytoplankton species in nearshore environments may be adapted to minimize the effects of iron stress, a characteristic generally attributed only to their oceanic counterparts. The only comparable data on Flv levels of which we are aware are those of Jones (1988), who reported that Flv represented $4 \%$ of the soluble protein for severely Felimited cells of the freshwater cyanobacterium Anabaena. We acknowledge the potential error associated with the use of Chlorella Flv II standards for HPLC-based quantification of our $T$. weissflogii Flv, but consider the error to be small. For example, the use of Anabaena Flv standard to quantify purified Chlorella Flv II resulted in only a $15 \%$ overestimate from values obtained using Chlorella Flv as a standard (G.J.D. \& D.L.E. unpubl. data).

The detection of a constitutive Flv in Thalassiosira weissflogii is not unique among those eukaryotic algae previously reported to synthesize this flavoprotein (Fitzgerald et al. 1978, Price et al. 1991), yet it is not clear what adaptive advantage is conferred by Flv in Fe-replete cells. Constitutive Flv isolated from the red algal species Chondrus crispus (Fitzgerald et al. 1978) is present at levels far above the corresponding Fd. By comparison, the flavodoxins of another red alga, Porphyra umbilicalis (Price et al. 1991), are considerably less abundant than $\mathrm{Fd}$ and thus more similar to the results obtained for $T$. weissflogii in this study. Given that such a broad range in the relative proportions of Flv and Fd is possible among eukaryotic marine algae, it appears unlikely that the role played by these various flavodoxins in cellular metabolism is identical. In cases where Flv reaches maximum concentrations under conditions of iron stress and the accompanying Fd levels are comparatively low, it is reasonable to think, based on numerous in vitro and in vivo studies, that the flavoprotein containing no iron replaces the iron-sulfur protein in certain metabolic pathways essential for cell growth and maintenance. This explanation likely applies to Fe-stressed $T$. weissflogii cells, and is consistent with the theoretical arguments of Morel (1987) that reductions in cellular iron quota (coupled with elevated maximum iron uptake rates) allow this species to maintain near maximum growth rates over a 300-fold range of free ferric iron activities.

\section{CONCLUSION}

Here we described the development of a new HPLC/PDA method for the separation and identification of Flv and Fd that allowed us to demonstrate unequivocally that the marine diatom Thalassiosira weissflogii produces substantial quantities of Flv in response to conditions of iron stress. This method can now be used to screen other marine phytoplankton species for this nutritional strategy, free from concerns about cross-reactivity and other limitations associated with immunodetection techniques. We also provided evidence for the constitutive expression of Flv by $T$. weissflogii, albeit at levels ca 10 -fold lower than those of Fd. $T$. weissflogii Flv represents the fourth constitutive Flv documented for a eukaryotic algal species. A simple index of Flv abundance relative to Fd showed good potential as an indicator of iron stress, even with constitutive Flv present. Additional laboratory and field studies are now needed to critically evaluate the applicability of Flv and $\mathrm{Fd}$ relative abundance as a diagnostic indicator of iron limitation in a broad range of species and natural phytoplankton communities.

Acknowledgements. We thank D. Kulis and B. Keafer for technical assistance, and J. J. Stegeman for the loan of equipment. The comments of 2 anonymous reviewers are appreciated. This work was supported in part by an Exploratory Research Agreement No. RP8021-05 from the Electric Power Research Institute Inc. (to D.M.A.), an NSERC Postdoctoral Fellowship and U.S. National Research Council-NOA.A/ NMFS Research Associateship (to G.J.D.), and by a DOE Graduate Fellowship for Global Change (to D.L.E.). This is contribution no. 8977 from the Woods Hole Oceanographic Institution

\section{LITERATURE CITED}

Brand LE, Sunda WG, Guillard RRL (1983) Limitation of marine phytoplankton reproductive rates by zinc, manganese, and iron. Limnol Oceanogr 28:1182-1198

Chisholm SW, Morel FMM (eds) (1991) What controls phytoplankton production in nutrient-rich areas of the open sea? ASLO Symposium. Limnol Oceanogr 36

Coale K, et al. (1994a) The Martin iron experiments: overview and iron chemistry. EOS 75:134

Coale K, et al. (1994b) The transient iron addition experiment: the phytoplankton response. EOS 75:134

Drummond MH (1985) The base sequence of the nif $\mathrm{F}$ gene of Klebsiella pneumoniae and homology of the predicted amino acid sequence of its protein product to other flavodoxins. Biochem J 232:891-896

Entsch B, Sim RG, Hatcher BG (1983) Indications from photosynthetic components that iron is a limiting nutrient in primary producers on coral reefs. Mar Biol 73:17-30

Fish W, Sanders-Loehr J (1987) Development of a field assay of iron limitation in nutrient rich lakes. Final Technical Completion Report, Project No. G1247-07, Oregon Water Resources Research Institute, Corvallis

Fitzgerald MP, Husain A, Rogers LJ (1978) A constitutive flavodoxin from a eukaryotic alga. Biochem biophys Res Commun 81:630-635

Harrison GI, Morel FMM (1986) Response of the marine diatom Thalassiosira weissflogii to iron stress. Limnol Oceanogr 31:989-997

Harrison PJ, Waters RE, Taylor FJR (1980) A broad spectrum artificial seawater medium for coastal and open ocean phytoplankton. J Phycol 16:28-35

Hutber GN, Hutson KF, Rogers LJ (1977) Effect of iron defi- 
ciency on levels of two ferredoxins and flavodoxin in a cyanobacterium. FEMS Microbiol Lett 1:193-196

Jones KL (1988) Analysis of ferredoxin and flavodoxin in Anabaena and Trichodesmium using fast protein liquid chromatography. MSc thesis, Portland State Univ, Portland, OR

Klugkist J, Voorberg J, Haaker H, Veeger C (1986) Characterization of three different flavodoxins from Azobacter vinelandii. Eur J Biochem 155:33-40

Knight JE, Hardy RWF (1966) Isolation and characteristics of flavodoxin from nitrogen-fixing Clostridium pasteurianum. J Biol Chem 241:2752-2756

Knight JE, Hardy RWF (1967) Flavodoxin: chemical and biological properties. J Biol Chem 242:1370-1.374

La Roche J, Geider RJ, Graziano LM, Murray H, Lewis K (1993) Induction of specific proteins in eukaryotic algae grown under iron-, phosphorus-, or nitrogen-deficient conditions. J Phycol 29:767-777

Martin JH (1990) Glacial-interglacial $\mathrm{CO}_{2}$ change: the iron hypothesis. Paleoceanography $5: 1-13$

Martin JH, Fitzwater SE (1988) Iron deficiency limits phytoplankton growth in the northeast Pacific subarctic. Nature 331:341-343

Martin JH, Gordon RM, Fitzwater S (1990) Iron deficiency limits phytoplankton growth in Antarctic waters. Global biogeochem Cycles 4:5-12

Martin JH, Gordon RM, Fitzwater S (1991) The case for iron. Limnol Oceanogr 36:1793-1802

This article was presented by D. A. Caron (Senior Editorial Advisor), Woods Hole, Massachusetts, USA.
Martin JH, Gordon RM, Fitzwater S, Broenkow WW (1989) VERTEX: phytoplankton/iron studies in the Gulf of Alaska. Deep Sea Res 36:649-680

Morel FMM (1987) Kinetics of nutrient uptake and growth in phytoplankton. J Phycol 23:137-150

Parsons TR, Maita T, Lalli CM (1984) A manual of chemical and biological methods for seawater analysis. Pergamon Press, New York

Price NT, Smith AJ, Rogers LJ (1991) Isolation of flavodoxin isoforms from a macroalga Porphyra umbilicalis and a conformational change on dissociation of flavin. Phytochemistry 30:2835-2839

Sandmann G, Peleato ML, Fillat MF, Lazaro CM, GomezMoreno C (1990) Consequences of the iron-dependent formation of ferredoxin and flavodoxin on photosynthesis and nitrogen fixation on Anabaena strains. Photosynth Res 26:119-125

Smillie RM (1965) Isolation of phytoflavin, a flavoprotein with chloroplast ferredoxin activity. Plant Physiol 40:1124-1128

Smillie RM, Entsch B (1971) Phytoflavin. In: San Pietro A (ed) Methods in enzymology, Vol 23. Academic Press, New York, p 504-514

Vetter H Jr, Knappe J (1971) Flavodoxin and ferredoxin of Escherichia coli. Z Physiol Chem 352:433-446

Zumft WG, Spiller H (1971) Characterization of a flavodoxin from the green alga Chlorella. Biochem biophys Res Commun 45:112-118

Manuscript first received: December 23, 1994

Revised version accepted: June 28, 1995 